\title{
O PARADOXO DA (IN) TOLERÂNCIA EM KARL POPPER E OS LIMITES- FRONTEIRAS DO DISCURSO DE ÓDIO
}

\author{
Juan Pablo Ferreira Gomes ${ }^{1}$
}

\section{RESUMO:}

O trabalho parte do "paradoxo da tolerância" de Karl Popper para investigar as fronteiras e os limites jurídicos ao que se concebe como (in) tolerante, no que passou a ser definido enquanto discurso de ódio na atualidade. Assim, aborda-se o que Popper considera como riscos da tolerância ilimitada e possibilidade de superação do conflito através da racionalidade no âmbito da linguagem, confrontando-se com a perspectiva e classificação adotada por Rainer Forst do conceito de tolerância e seus respectivos limites, bem como sua adequação jurídica quanto ao tratamento dado ao "discurso de ódio" como definido e explorado por Jeremy Waldron.

Palavras-Chave: Paradoxo; Tolerância; Limites; Discurso de Ódio; Linguagem.

\section{THE PARADOX OF (IN)TOLERANCE IN KARL POPPER AND THE BORDER LIMITS OF HATE SPEECH}

\begin{abstract}
:
The paper has its starting point from the "paradox of tolerance" by Karl Popper, intending to investigate the limits and juridical boundaries to what is perceived as (in)tolerant, to what is nowadays defined as "hate speech". Thereafter, this work approach what Popper considers as risks of unlimited tolerance and the possibility of overcoming the conflict through rational language, confronting with Rainer Forst's perspective and classification of the very own concept of tolerance and its respective limits, along with its juridical (in)adequacy regarding the approach given to "hate speech" by Jeremy Waldron.
\end{abstract}

Keywords: Paradox; Tolerance; Limits; Hate Speech; Language;

\section{O PARADOXO E OS LIMITES DA (IN) TOLERÂNCIA EM KARL POPPER}

A concepção de tolerância enquanto conceito, princípio, valor, virtude ou instituto jurídico possui sua genealogia discursiva própria em toda sua complexidade, sendo ora tomada enquanto categoria racional nas relações intersubjetivas ${ }^{2}$.

\footnotetext{
${ }^{1}$ Advogado. Professor. Escritor. Doutorando em Ciências Jurídico Filosóficas pela Universidade de Coimbra UC. Mestre em Direito Ambiental pelo Programa de Pós-Graduação em Direito Ambiental da Universidade do Estado do Amazonas - UEA. Especialista em Processo Judiciário Penal pela Escola Superior da Advocacia no Amazonas - ESA/AM. Bacharel em Direito e Habilitado em Direito Internacional pela Universidade do Estado do Amazonas - UEA. Email juanpablogomes1 @ gmail.com.

${ }^{2}$ Vide GAUDÊNCIO, Ana Margarida Simões. "O intervalo da tolerância nas fronteiras da juridicidade: fundamentos e condições de possibilidade da projecção jurídica de uma (re)construção normativamente
} 
Em Karl Popper, na dinâmica do progresso da ciência e do conhecimento, bem como em face da persecução de uma verdade objetiva, seria essencial o compromisso entre a máxima tolerância em relação às conjecturas e a máxima tolerância para com as tentativas de refutação destas, levando-se ao plano das relações sociais a tolerância, ligada ao falibilismo e ao racionalismo na organização da vida política e social ${ }^{3}$.

Tal perspectiva resultaria na conjugação de três princípios: 1) "I may be wrong and you may be right" - admitindo-se uma verdade objetiva e, concomitantemente, que um ou ambos os sujeitos estejam errados, porém não já ambos corretos; 2) «by talking things over rationally we may be able to correct some of our mistakes" - pressupondo-se diretamente a tolerância, e compreendendo a racionalidade como prossecução dialógica daquela verdade; 3 ) "If we talk things over rationally, we may both get nearer to the truth" - admitindo-se a manutenção do desacordo após a discussão racional, com o objetivo de aproximação da verdade, ainda que não resultando em acordo, todavia permitindo a tolerância mútua ${ }^{4}$, de tal modo que se possa retirar da discussão o avanço, garantindo-se a compossibilitação das diferenças, sem dominação hegemônica ${ }^{5}$.

Ou seja, a tolerância é reconhecida como valor necessário e desejável ante a objeção ou oposição de ideias e perspectivas, mesmo quando estas tendem a negá-la ou possam ser reconhecidas em seu valor oposto na condição de (in) tolerantes, devendo então ser

substancial da exigência de tolerância". Coimbra, Portugal: Instituto Jurídico da Faculdade de Direito da Universidade de Coimbra. 2019

3 POPPER, Karl. "The Open Society and Its Enemies", vol. I, "The Spell of Plato" e vol. II - The High Tide of prophecy: Hegel, Marx, and the Aftermath (1945), Princeton University Press, New Jersey, 1971.

4 “'(...) it is very good to say, 'I may be wrong and you may be right'; and if both parties say it, it may even suffice for mutual toleration, and for a good society. But in order to avoid relativism we have to say more than this. What we should say is: 'I may be wrong and you may be right; and by talking things over rationally we may be able to correct some of our mistakes and we may perhaps, both of us, get nearer to the truth, or to acting in the right way'.

(...) I will (...) divide my formulation into three parts; or, I suggest, into three principles(...)

THE FIRST PRINCIPLE

I may be wrong and you may be right

(...) far from implying that - if you and I differ, we may both be right - it implies that there may be a right and a wrong view of whatever the issue is; and that, indeed, we may both be wrong. -

THE SECOND PRINCIPLE

By talking things over rationally we may be able to correct some of our mistakes

(...)

I will first explain what I mean by 'talking things over rationally'. I mean by this, talking things over with the aim of finding out what is true and what is false; and what is wrong and what is right (...)

THE THIRD PRINCIPLE

If we talk things over rationally, we may both get nearer to the truth

The main point here is the idea of getting nearer to the truth, perhaps even if we do not agree (...)

The third principle is that, by talking, we may both get nearer to the truth, even if we may not reach agreement. It is clear that this can be achieved, in a discussion, only by mutual tolerance (...)" Idem, p. 26-29.

${ }^{5}$ GAUDÊNCIO, Ana Margarida Simões, Obra Citada. 
rechaçadas, racionalmente, através do processo argumentativo, não sendo prudente a mera proibição daquilo que se tem como não tolerante.

A antinomia que passa a ser reconhecida como paradoxo da tolerância, apresentada por Popper em seu livro "The Open Society and Its Enemies", publicado no ano marcado pelo desfecho da Segunda Guerra e derrocada do nazifascismo, estaria na ameaça, apresentada pela tolerância ilimitada, de levar ao desaparecimento da própria tolerância, sucumbida pela sua condescendência com ideias ou valores tidos como (in)tolerantes.

Assim, o direito à proibição das ideias intolerantes poderia ser reivindicado em nome da manutenção da própria tolerância e defesa da sociedade. A sociedade tolerante deveria estar sempre alerta ante o assalto da (in)tolerância, seja com argumentos racionais ou mantendo expressões (in)tolerantes em xeque frente à opinião pública, reservando-se o direito de suprimi-las, se necessário, mesmo que pela força.

Não obstante a própria complexidade da definição dos sujeitos, objeto, fundamento, condições de possibilidade e conteúdo da categoria tolerância, o seu reflexo normativo mesmo enquanto conteúdo positivamente material encontrará nos seus limites e critérios do que é (in) tolerável a preocupação precípua de nossa reflexão.

\section{O CONCEITO DE TOLERÃNCIA E A CLASSIFICAÇÃO DE RAINER FORST}

Na linha proposta por Popper, considerando a tolerância o resultado de uma atitude de não reação em face de um comportamento-ideia de que se discorda, o seu conteúdo normativo dependerá, em última instância, da definição dos seus limites-fronteiras. Limites estes das mais diversas naturezas de ordem subjetiva e objetiva, sob uma perspectiva ética ou moral, tanto quanto prático-jurídicos, desaguando-se em múltiplos paradoxos e aporias que não podem prescindir de uma desconstrução analítica, sob pena de se recair em um relativismo irrefletido ou em abusos arbitrários hábeis a esvaziar a própria categoria em si.

Em diálogo com Popper, dentre as mais diversas enunciações e classificações sobre a concepção de tolerância e seus respectivos paradoxos, toma-se como referencial as problematizações de Rainer Forst para uma demarcação da categoria tolerância ora em construção.

Na sistematização de Forst, há uma paradoxalidade da noção de tolerância em si mesma, enquanto não reação a comportamentos errados ou reprovados, em virtude de razões 
superiores determinantes da ausência desta reação, localizando-se entre a objeção ante determinados comportamentos, bem como a sua não completa rejeição em virtude de princípios superiores justificantes ${ }^{6}$.

Nesta perspectiva, os limites da tolerância situar-se-ão na linha em que as razões de rejeição sejam mais fortes do que as razões de aceitação, encontrando-se envolvidas duas fronteiras: a primeira situada entre o domínio normativo das práticas e convicções objeto de concordância e o das práticas toleráveis, consideradas erradas, mas susceptíveis de continuarem a não ser rejeitadas.

Assim, neste segundo domínio se firmaria o intolerável, o estritamente rejeitado (o limite da tolerância propriamente dito), de tal modo que existiriam, neste sentido, conforme a enunciação aqui pressuposta, três, e não apenas dois, domínios normativos num contexto de tolerância ${ }^{7}$ : estabelecendo-se o fundamento de determinação da fronteira entre aceitação, não rejeição e rejeição, constituindo-se por si só, resolução para o paradoxo da tolerância em si mesma, permanecendo este, apenas, então, como paradoxo aparente. A necessária delimitação das fronteiras da tolerância (grenzen der toleranz) exigiria, para Forst, o terceiro componente da tolerância: o componente de rejeição (zurückweisungskomponente - rejection componente).

Primeiramente, o contexto da tolerância precisa ser especificado. "Qual é a relação entre o tolerante e o tolerado (por exemplo, pais e filhos, amigos, cidadãos etc.)? Quais são os sujeitos (indivíduos, grupos, o Estado) e os objetos (crenças, ações, práticas) da tolerância?” 8

Em segundo, é essencial para o conceito de tolerância que as crenças ou as práticas toleradas sejam consideradas objetáveis e erradas ou más em um sentido relevante. Se esse componente de objeção estiver faltando, não falaremos de "tolerância", mas de "indiferença" ou "afirmação".

Em terceiro lugar, o componente de objeção precisa ser balanceado por um componente de aceitação, que não remove o juízo negativo, mas fornece algumas razões positivas que superam as negativas em um contexto relevante. "De acordo com essas razões, seria errado não tolerar o que é errado, para mencionar outro paradoxo bem conhecido da

\footnotetext{
${ }^{6}$ FORST, Rainer. "The Limits of Toleration", in Constellations, vol. 11, 2004, 312-325 (versão inglesa de Rainer FORST, "Grenzen der Toleranz", in Winfried BRUGGER/Görg HAVERKATE, Grenzen als Thema der Rechts- und Sozialphilosophie, Archiv für Rechts- und Sozialphilosophie, 1998, Beiheft 84;

${ }^{7}$ GAUDÊNCIO, Ana Margarida Simões. Obra citada.

${ }^{8}$ FORST, Rainer. "The Limits of Toleration", in Constellations, vol. 11, 2004, 312-325 (versão inglesa de Rainer FORST, "Grenzen der Toleranz", in Winfried BRUGGER/Görg HAVERKATE, Grenzen als Thema der Rechts- und Sozialphilosophie, Archiv für Rechts- und Sozialphilosophie, 1998, Beiheft 84
} 
tolerância. As práticas ou as crenças em questão são erradas, mas não intoleravelmente erradas"

Em quarto, os limites da tolerância precisam ser delimitados. Eles ficam em um ponto no qual as razões para a rejeição se tornam mais fortes do que as razões para a aceitação (o que ainda deixa em aberto a questão dos meios apropriados para uma possível intervenção).

Sob esse viés, nos limites da prática de tolerância, os intolerantes não necessitariam ser (nem poderiam) ser tolerados, ideia dominante nas reflexões das mais diversas índoles sobre a categoria tolerância, conforme conclusão do próprio Popper: "unlimited tolerance must lead to the disappearance of tolerance. If we extend unlimited tolerance even to those who are intolerant, if we are not prepared to defend a tolerant society against the onslaught of the intolerant, then the tolerant will be destroyed, and tolerance with them" ${ }^{\prime \prime}$.

Todavia, o caráter vago e impreciso do mandamento "não tolerar o intolerante" se apresenta como potencialmente perigoso, posto que a definição de intolerante será muito frequentemente resultado de unilateralidade e intolerância suscitando os paradoxos da autodestruição (paradoxie der selbstzerstörung) e da delimitação (paradoxie der grenzziehung) - provocados pelo fundamento da rejeição, o primeiro a significar que a tolerância não fundamentada, ilimitada, corre o risco de se autodestruir, o segundo a determinar a imperatividade da delimitação da tolerância, sob pena de esta se reverter no seu contrário.

Não por outro motivo, para Popper haveria que se conferir alguma liberdade às minorias intolerantes, no sentido de lhes permitir a publicitação das suas teorias como propostas racionais, contudo tal tolerância terminaria no ponto em que tais minorias se tornassem violentas, pondo em causa a estrutura democrática ${ }^{11}$.

\footnotetext{
${ }^{9}$ Obra citada.

10 "tolerância ilimitada tem de conduzir ao desaparecimento da tolerância. Se alargarmos a tolerância ilimitada mesmo àqueles que são intolerantes, se não estivermos preparados para defender uma sociedade tolerante contra a ofensiva dos intolerantes, então os tolerantes serão destruídos, e com eles a tolerância" POPPER, Karl. Obra citada, p. 265.

${ }^{11}$ POPPER, Karl - "Toleration and Intellectual Responsibility", in Susan MENDUS, David EDWARDS, On Toleration, Clarendon Press, Oxford, 1987, p. 18-19. «(...) minorities (...) who are unwilling to reciprocate the tolerance offered to them by the majority: minorities who accept a principle of intolerance; who accept a theory of the necessity of violence and who may even act violently. These minorities, we have reason to think, would try to abolish democracy, freedom of speech, and toleration, if they succeeded in gaining power even for a day». - Idem, p. 18. «(...) as long as these intolerant minorities discuss and publish their theories as rational proposals, we should let them do so freely. But we should draw their attention to the fact that toleration can only exist on a basis of mutuality, and that our duty to tolerate a minority ends when the minority begins to act violently. The question arises: Where does rational debate end and violent action begin? This will not be easy to decide in
} 
Acontece que a contemporaneidade assiste atordoada a ascese da violência simbólica articulada e implícita ao próprio discurso enquanto manifestação ou livre expressão do pensamento, o que nos conduz aos aspectos relativos ao discurso de ódio.

\section{LIBERDADE DE EXPRESSÃO E DISCURSO DE ÓDIO: APONTAMENTOS DE JEREMY WALDRON}

Um dos elementos característicos e fundantes da Modernidade, no que se refere à dignidade humana, foi a afirmação da liberdade como valor essencial à condição humana. Tal expressão pressupõe uma sociedade pautada na não ingerência ilegítima de terceiros em assuntos e demandas individuais, de modo a garantir a qualquer sujeito a realização de seus próprios objetivos, sem o dever de obediência a outrem por razões que não se firmem na razão e na legalidade.

Com efeito, a consciência da liberdade como um poder de autodeterminação necessário à dignidade do ser humano é contemporânea às concepções ideológicas liberais do século XVIII, marcadas pela afirmação da burguesia frente ao absolutismo da monarquia de então.

É importante ressaltar, como pondera Coulanges, que a liberdade então para os gregos era unicamente a prerrogativa conferida aos cidadãos de participar das decisões políticas e nisso diferenciava-se do liberalismo clássico ${ }^{12}$.

O modelo discursivo então promovido pelos liberais consistia na consagração formal das liberdades (em declarações de direitos e cartas constitucionais) objetivando unicamente a proteção da autodeterminação individual quase absoluta, oponível somente ao Estado, ressaltando apenas o caráter negativo da tutela jurisdicional.

Ao longo do século XIX, o modelo liberal pautado pela tutela predominantemente negativa passa a coexistir-concorrer com o modelo de Estado Social que além de propor uma tutela restritiva (negativa), sustenta uma agenda protetiva (positiva), em termos sociais, buscando compatibilizar o exercício das liberdades com o que se consideram necessidades da coletividade.

practice, for it begins with such acts as incitement to violence or conspiracy to overthrow the democratic constitution». - Idem, p. 19.

${ }^{12}$ COULANGES, F. A cidade antiga. Tradução de Fernando de Aguiar. Lisboa: Clássica, 1971. 
Nesse sentido, observa-se que a liberdade, quanto ao seu conteúdo, passou a ser caracterizada como a não submissão a outrem, no fato de não estar sob o controle de terceiros, de não sofrer restrições impositivas, venham elas do Estado ou de outro indivíduo.

Verifica-se, portanto, uma inequívoca conotação de restrição dirigida a todos em sociedade, assegurando ao indivíduo o exercício da sua autodeterminação. "Liberdade é a ausência de todo e qualquer constrangimento"13.

Nesse sentido, Isaiah Berlin apresenta duas perspectivas para o conceito de liberdade: a liberdade negativa, opositora a todo o tipo de ingerência, e nesse aspecto em nada difere da grande maioria dos doutrinadores (freedom of), e a liberdade positiva, "freedom to", enfocando a liberdade como participação política ${ }^{14}$.

Assim, a liberdade, enquanto inserida e tutelada pelo ordenamento jurídico, encontra seu contraponto na legalidade, uma vez estabelecidos oferece os limites de atuação e escolha. Objetiva-se que o indivíduo poderá, no exercício da liberdade, escolher livremente até encontrar uma lei que lhe imponha uma obrigação ou uma proibição. Deverá então autodeterminar-se até que uma lei disponha em sentido contrário ao de sua escolha. Em outros termos, proibição e a obrigação quando objeto de lei (espécie normativa originada do legislativo) constituem os limites ao exercício da liberdade.

Em tais contornos, o "constitucionalismo", como movimento proclamador de uma nova estrutura organizacional para os Estados, busca afastar definitivamente os regimes absolutistas e estabelecer as bases para a implementação das democracias modernas. Com pretensões jurídico-políticas, esse movimento teve por objetivo implantar, por meio das cartas constitucionais escritas, um sistema que, ao mesmo tempo, pudesse estabelecer limites irreversíveis ao exercício do poder do Estado e garantir, em contrapartida, os direitos essenciais do cidadão.

Mais do que um simples movimento em defesa das constituições, o constitucionalismo se articulou como proposta política de cunho ideológico/revolucionário com vistas a promover limites ao exercício do poder da monarquia absolutista, para garantir em contrapartida, o mais amplo poder de autodeterminação para a burguesia emergente. Dessa forma, quando se considera a dimensão social e política do movimento constitucionalista, a partir de meados do século XVIII, deve-se, sobretudo, ressaltar sua importância para as

\footnotetext{
${ }^{13}$ BURDEAU, G. Les libertés publiques. 4. ed. Paris: Press Universitaires de France, 1972.

${ }^{14}$ BERLIN, I. Quatro ensaios sobre a liberdade. Tradução de Wumberto Hudson Ferreira. Brasília, DF: Ed. da UNB, 1981.
} 
revoluções liberais e para a ascensão da burguesia que constituíram referências relevantes para a derrocada do absolutismo e a definição do paradigma liberal clássico.

Por conseguinte, o segmento social burguês, expressivo em termos econômicos, sempre teve como referência central a luta em defesa das liberdades como valor essencial à dignidade humana e a construção de um Estado com ingerência mínima quanto ao poder de autodeterminação de seus cidadãos, especialmente no que pertine suas convicções: o Estado Gendarme.

Em John Locke, na epístola sobre a tolerância, resta expresso o vaticínio que o poder político não deve emitir juízos sobre religião, por não ter legitimidade ou competência para elaborar conceitos em matéria de fé. Doutro giro, a Igreja deve se restringir ao campo exclusivamente espiritual, por meio do culto a Deus, sem qualquer ingerência em bens terrenos e, sobretudo, não utilizar da força como elemento de persuasão. A adesão à fé deve advir espontaneamente, pela formação livre de uma convicção religio sa ${ }^{15}$.

John Milton, em sua obra Areopagítica, defende a liberdade de expressão como livre discussão de ideias e expõe suas críticas à coação como forma de impor uma vontade externa. Também aponta os livros como repositórios da sabedoria da vida, considerando a censura um homicídio à própria razão ${ }^{16}$.

Em França, Voltaire, com supedâneo no assassinato de Marc Antoine, filho de Jean Calas, pelo seu próprio pai, para impedi-lo de converter-se ao catolicismo, redige um libelo em nome da liberdade de expressão e convicção religiosa ${ }^{17}$.

Uma vez descartada a monarquia absolutista com a construção do Estado mínimo e a divisão das funções do poder estatal, estabelecida em cartas constitucionais, e ainda afastada a ingerência da Igreja em assuntos políticos, pode então a burguesia ascender de forma irreversível ao cenário político da modernidade.

Essas transformações, aparecem firmadas nas Declarações de Direitos posteriores às Revoluções Liberais. A Revolução Americana de 1776 proclama as Declarações de Direitos dos Estados Americanos de 1776 e dá lugar à edição da Declaração da Virgínia de 1776. A liberdade de convicção religiosa acha-se mencionada no seu artigo 16. A igualdade formal também vem garantida na seção 4, e o artigo 12, por sua vez, positiva a liberdade de imprensa como garantia à liberdade de expressão. Em 1789, a Declaração de Direitos do Homem e do

\footnotetext{
${ }^{15}$ Cartas acerca da tolerância: segundo tratado sobre o Governo. São Paulo: Abril Cultural, 1973.

16 Aeropagítica. Cambridge Press, 1918.

17 Tratado sobre a tolerância: a propósito da morte de Jean Calas. 2. ed. São Paulo: Martins Fontes, 2000.
} 
Cidadão, lança os fundamentos para a afirmação da ordem liberal, conclamando a relevância das constituições para esse propósito (artigo 16), havendo clara opção pelo laicismo, estabelecendo (artigo 10) a liberdade de opinião, inclusive a religiosa, desde que a sua manifestação não confronte a ordem pública.

Com a afirmação das concepções liberais seguiu-se um período extremamente propício à concentração de capital e ao desenvolvimento tecnológico, entretanto, é forçoso reconhecer que a evolução gerada pela implementação do ideário liberal não se deu de forma linear. Ao contrário, a capacidade para a concentração de riqueza criou condições favoráveis ao surgimento das crises cíclicas na economia do mundo ocidental, evidenciando as contradições do sistema econômico liberal.

A partir de então foi possível observar a afirmação do paradigma de intervenção estatal em substituição da ordem liberal de intervenção mínima e da emergência do Estado Social de corte intervencionista com escopo de solucionar as falhas da liberdade de mercado.

Para tanto, o Estado passou ao reconhecimento das assimetrias sociais, promoveu o controle da economia (incentivando seus setores vitais) e procurou implementar a justiça redistributiva necessária à pacificação dos conflitos sociais.

O reconhecimento pelo Estado Social de novos atores, com expectativas específicas, distintas das tradicionais demandas burguesas (o proletariado) levou à reconfiguração do conteúdo da dignidade humana pela incorporação de novos direitos (direitos sociais) oriundos das reivindicações dos grupos sociais subalternos ${ }^{18}$.

Assim, constata-se a incorporação paulatina dos direitos sociais ao rol das liberdades já assimiladas pelo conteúdo da dignidade humana, como forma de administrar o conflito capital/trabalho. Posteriormente, já na década de 1990, mais conhecida como a época do "póssocialismo", observa-se uma realidade bastante distinta no que se refere à esfera social. A fragmentação do tecido social tornou-se evidente com a emergência de grupos organizados, com reivindicações próprias, que imprimiram modificações profundas à sociedade contemporânea.

Em verdade, essas novas expectativas geraram solicitações que privilegiaram sobretudo as diferenças existentes entre os vários setores sociais, confrontando-os com os valores tradicionais que atribuíram ao Estado a responsabilidade pela minoração das desigualdades, deixando em segundo plano a diversidade.

\footnotetext{
${ }^{18}$ ROSANVALLON, Pierre. A crise do Estado-Providência. Goiania: Editora da UFG, 1997.
} 
Esse descompasso entre o valor básico que fundamentou o Estado Social, qual seja: a diminuição das desigualdades sociais e os valores denominados "pós-materialistas", que buscam, sobretudo, qualidade de vida (ecologia, lazer etc.), muito contribuiu para a transformação dos Estados intervencionistas de cunho social.

Dessa forma, outros tipos de injustiças, para além da luta do proletariado se fizeram presentes e buscaram seu reconhecimento, pontuando descontentamentos e distorções que não seriam solucionados unicamente por meio da justiça redistributiva.

Com o advento das redes sociais, tais pautas ganharam expansão discursiva e, em efeito contrário, vozes reativas encontraram eco em uma escalada de acirramento de ânimos e acentuada tensão social para muito além do reconhecimento ou aporia inevitável decorrente de diferenças culturais e ideológicas.

Sob o escudo da liberdade de expressão, discursos programáticos voltados para a violência, alijamento ou extermínio são articulados e reverberados através do aparato de propagação decorrente do advento da rede mundial de computadores.

O discurso do ódio (hate speech) é ora entendido como qualquer ato de comunicação que incite ou fomente o ódio contra determinado grupo ou indivíduo em razão de raça, gênero, etnia, nacionalidade, religião, orientação sexual ou outro aspecto passível de discriminação, enquanto expressão do pensamento e de acordo com Jeremy Waldron passando a gerar efeitos nocivos que poderão perdurar no tempo de acordo com o veículo de transmissão utilizado ${ }^{19}$.

É imperioso observar que tal discriminação indica não apenas uma diferença, mas uma assimetria entre duas posições: uma supostamente superior, daquele que expressa o ódio e outra inferior, daquele contra o qual a rejeição é dirigida.

O objetivo pretendido é humilhar para amedrontar pessoas ou grupos sociais evidenciando que, por suas características específicas, não são dignos da mesma participação política. Não apenas eliminar, mas calar, excluir e alijar são propósitos da manifestação do ódio.

Nesse sentido, tolerar o discurso enquanto catalizador e propagador de um ideário por si só afeta grupos e indivíduos em condição de vulnerabilidade que se veem forçados a tolerar

\footnotetext{
${ }^{19}$ WALDRON, Jeremy. Dignity and Defamation: the Visibility of Hate. Harvard Law Review, v.123, n.1596, p. 1597-1657, 2010.
} 
o intolerante em nome da liberdade de expressão enquanto princípio normativo ou valor éticomoral relevante dentro de uma sociedade.

Curiosamente alguns autores como Simon Lee $^{20}$, atribuem a Voltaire a responsabilidade pela defesa do discurso do ódio, enquanto manifestação legítima do pensamento, necessária à afirmação da democracia. Para estes casos a tolerância deveria provir dos setores discriminados que suportariam as ofensas originadas dos discursos em nome da defesa da democracia.

Com efeito, a democracia radicalmente liberal contemplaria a liberdade de expressão exercida em sua plenitude, compreendendo inclusive a manifestação do ódio. Assim haveria prevalência da liberdade de expressão sobre a dignidade dos ofendidos.

Doutro giro, a aceitação de discursos do ódio, legitimaria a competição entre eles, sempre com a crença de que o melhor discurso prevaleceria, cabendo aos ofendidos aguentar os efeitos violência levada a efeito.

No mesmo turno, é imperioso sopesar a assimetria de peso quando se pondera a origem do discurso quanto ao agente que o promove e o impacto de sua fala no tecido social e a ameaça de tal articulação para as instituições democráticas e grupos apontados como alvos.

Não há como se atribuir o mesmo efeito na expressão odienta de um anônimo comentando notícias nas redes sociais (o agente que passou a ser conhecimento como hater ou troll) com a fala de um Chefe de Estado que, mesmo não movendo a máquina estatal no cumprimento do que articula, chancela ou legitima ações violentas daqueles que coadunam com determinado valor (in) tolerante.

Considerando apenas as democracias liberais contemporâneas tornaram-se notórios o teor de ódio dos discursos promovidos pelo então presidente Donald Trump, nos Estados Unidos da América, bem como de Jair Bolsonaro, no Brasil, contra grupos minoritários, inclusive pautando suas respectivas campanhas e políticas públicas nesse sentido, além de incentivar e reforçar grupos de apoiadores que sustentam e compactuam do mesmo ideário, reiteradamente incitando seus partidários a reagir contra as instituições e os demais poderes quando contrariados ou por conveniência política.

É interessante observar que estes mesmos grupos, invocam a necessidade da restrição da liberdade de expressão contra adversários ou correntes ideológicas antagônicas, como quando se pretendeu a supressão do Partido Comunista nos Estados Unidos, sob a justificativa

\footnotetext{
${ }^{20}$ LEE, Simon. The Cost of Free Speech. Londres: Faber and Faber, 1990.
} 
da necessidade de inviabilizar a propagação do stalinismo durante a Guerra Fria e a tentativa recente de se criminalizar o comunismo no $\mathrm{Brasil}^{21}$.

Em suma, torna-se imperioso e inarredável considerar as relações estratégicas de poder, que de forma pragmática, são articuladas em nome de categorias discursivas abstratas. Como bem salienta Forst, "sempre necessário se indagar quem estabelece esses limites e contra quem, com base em que razões, e quais motivações estão em jogo. Em suma, quem quer que fale de tolerância não pode silenciar quanto ao poder"22.

Assim dois significados de "intolerância" precisam ser necessariamente distinguidos: a intolerância dos que se colocam além dos limites da tolerância, porque recusam a tolerância como norma em princípio, e a intolerância dos que não querem tolerar a recusa dessa norma. Considerar, assim, ambos os pontos de vista igualmente de "intolerantes", pressupõe que não haja um modo não-arbitrário, imparcial de demarcar os limites da tolerância.

Como bem salienta Forst, "para que o conceito de tolerância seja salvo desse paradoxo destrutivo, deve existir tal possibilidade, só assim pode a crítica a uma (possível) ação contra a 'intolerância' ser ela mesma mais do que apenas outra forma de 'intolerância",23.

Uma vez pontuada tal ressalva, é impositivo considerar aspectos relativos à (ir) relevância jurídica de tais expressões de intolerância, ou quando é inevitável ao direito, enquanto ordenamento jurídico, exercer tutela ou pronunciar-se sobre determinado acontecimento.

Para Kaufmann, por exemplo, o posicionamento desse limite não está necessariamente na intolerância, mas apenas na intolerância que ponha em perigo a liberdade ${ }^{24}$.

Neste sentido, também Luís Nunes de Almeida, sustenta que o limite da tolerância não será simplesmente a intolerância, ou o intolerante de forma abrangente ou genérica, o comportamento intolerante só não deverá ser tolerado se e quando puser em causa "a liberdade ou, em geral, as condições de possibilidade da tolerância". ${ }^{25}$

\footnotetext{
${ }^{21}$ FISS. Owen M. A Ironia da Liberdade de Expressão: Estado, Regulação e Diversidade na Esfera Pública. Rio de Janeiro: Ed. Renovar, 2005.

${ }^{22}$ FORST, Rainer. Os limites da tolerância. Novos estud., CEBRAP, São Paulo, n. 84, 2009, p. 15-29.

${ }^{23}$ FORST, Rainer. Obra citada.

24 KAUFMANN, Arthur - "Rechtsphilosophie", C. H. Beck, München, 1997, também citado na tradução portuguesa "Filosofia do Direito", tradução de ULISSES CORTÊS, Antônio. Fundação Calouste Gulbenkian, Lisboa, 2004;

${ }^{25}$ ALMEIDA, Luís Nunes de - "Tolerância, Constituição e Direito Penal”, in Revista Portuguesa de Ciência Criminal, ano 13, n. ${ }^{\circ}$, Abril-Junho 2003, p. 159-175.
} 
A questão fundamental na contemporaneidade está situada na (im) possibilidade de delimitação ou previsão clara de quando a liberdade ou as condições de possibilidade da tolerância estão ameaçadas, ou quando a fronteira do tolerável é ultrapassada e uma reação jurídica a um determinado comportamento-discurso se torna urgente-necessária.

$\mathrm{Na}$ considerada sociedade da hiperinformação, superprodução, superdesempenho e supercomunicação uma nova arquitetura da violência ganha contorno.

Jean Baudrillard, nos anos noventa do século passado, assinalava a "obesidade de todos os sistemas atuais", num totalitarismo do igual e do mesmo, a partir de uma perspectiva imunológica: "não é por acaso que se fala tanto de imunidade, anticorpos. De inseminação e aborto. Em tempos de carestia, a preocupação está voltada para a absorção e assimilação. Em épocas de superabundância, o problema volta-se mais para a rejeição e expulsão. A comunicação generalizada e a superinformação ameaçam todas as forças humanas de defesa" $" 26$.

Tal perspectiva é crucial para se compreender a violência viral-virtual, "uma violência da aniquilação suave, uma violência genética e de comunicação; uma violência do consenso",27.

Nesse sentido, mesmo a "cultura da diferença" tenderia a negar a alteridade radical do outro em nome de valores humanistas pretensamente universais.

Mais recentemente, ressaltando a transição de uma época marcada pelas relações dentro-fora, ataque-defesa, próprio-estranho, características do século XX, para uma diferença pós-imunológica pós-moderna na qual se extingue a alteridade (outro) em favor do diferente (mesmo), Byung-Chul Han pondera sobre os adoecimentos neuronais (estados patológicos do excesso de positividade e estímulos) típicos do século $\mathrm{XXI}^{28}$.

O excesso da sociedade do acúmulo e da saturação, da superabundância recairia sobre os indivíduos na forma de fardo, de exaustão insuportável, cumulando em uma tensão não aplacada, mas intensificada pela ausência de negatividade.

Curiosamente, o mesmo Popper da sociedade aberta identifica já no período helênico uma tensão entre o que identifica como sociedade fechada, agarrada ao tribalismo mágico e a

\footnotetext{
${ }^{26}$ BAUDRILLARD, Jean. Die Transparenz des Bosen - Ein essay uber extreme phânomene. Berlim, 1992, p. 75 .

${ }^{27}$ Obra citada, p. 54.

${ }^{28}$ HAN, Byung-Chul Sociedade do Cansaço. Petrópolis, RJ: Vozes, 2017. p. 20-21.
} 
não individualização, tal qual o modelo espartano e a estrutura universalista expansiva ateniense, cosmopolita, aberta e individualista.

Em certa medida, a experiência totalitária, em Popper, reflete o impulso recorrente de uma sociedade tensa e dividida que se nota decadente e busca um paraíso perdido pelo fim da experiência tribal, oferecendo sempre uma ideologia ou modelo social a ser alcançado como remédio totalizante e arbitrário mesmo que imbuído das melhores "intenções", tal qual a utopia republicana de Platão, reconhecido como um herdeiro ateniense dos anseios oligarcas em declínio.

Desse modo, passando por Hegel e Marx, a sociedade contemporânea não se diferiria em tensão de classes e interesses, no processo de sua respectiva abertura, da sociedade helênica, encontrando-se volta e meia algozes e vozes contrárias a tal dinâmica.

A alternativa popperiana se situaria, grosso modo, no que considera um racionalismo crítico herdeiro do humanitarismo legado pelos gregos e tendo em figuras como Sócrates e Péricles seus grandes campeões.

$\mathrm{Na}$ busca bela verdade, na confiança da razão e comunicação, no respeito à individualidade, naquilo que identifica como traços e valores de uma sociedade aberta e plural, teríamos o caminho da tolerância enquanto experiência coletiva, exercendo o direito papel reflexo de uma convenção entre todos, prescindindo-se de um anteparo natural, metafísico, não empírico, ou abstração teórica como a concepção idealizada de um contrato social.

Acontece que, como toda convenção, há uma pressuposição ou expectativa de, ainda que não totalmente assimilada, tal regra ou comando refletir a expectativa ou anseio de uma coletividade em tal valor, ou ainda na validade e utilidade mínima daquele dispositivo legal.

$\mathrm{Na}$ sociedade performático-discursiva em nome da verdade, da justiça, do bem-estar, da felicidade coletiva, as maiores atrocidades são promovidas e sustentadas por grupos e indivíduos que, em inúmeras situações, se arrogam e se reconhecem providos das melhores intenções e boa-fé, ou ainda identificando as "regras do jogo", emulam enunciados aceitos e tolerados articulando-se na forma de um "deep state" ou "gabinete do ódio", num paralelismo não alcançável pelo ordenamento jurídico, minando as instituições impotentes e impassíveis.

\section{CONCLUSÃO}


É consenso em qualquer noção acerca do multiculturalismo a expectativa de integração de todos os cidadãos e o reconhecimento recíproco das suas particularidades, inobstante o pertencimento à mesma comunidade política, pelo que se espera o reconhecimento da diferença e os seus limites se encontrem no ordenamento jurídico.

Todavia, a experiência coletiva contemporânea, denominada (ou não) de pós-moderna, demonstra, se não um esgotamento, uma crise de paradigmas e uma descrença generalizada em um cada vez mais difuso e desbotado projeto moderno de racionalidade e consenso.

Grupos minoritários e vulneráveis, mesmo em sociedades que supostamente introjetaram esse modelo de conciliação social, são lançados em uma degenerada democracia convertida em "ditadura da maioria", não havendo precedente que garanta que o direito possa dar conta do exercício da tutela do que se pretende enquanto instrumento de pacificação social.

Estaria o modelo alicerçado no contrato social ruído ou a urgência do debate de tais aspectos apenas reforça a não conclusão do projeto moderno-liberal? Como as instituições e o direito reagirão ao impacto nos próximos anos de uma evidente polarização social e discursiva que lança dúvidas contra pressupostos até então tidos como mínimos para vida em sociedade?

É necessário identificar os caminhos e vias que passam e perpassam forçosamente pelo direito sem recair em velhos dilemas e aporias que não recaiam em tautologias ou soluções simplórias divorciadas da tensão social que experimentamos ou não reconhecimento do drama inerente ao que Kaufmann denomina como "ponto de viragem" de nossa experiência social contemporânea, tendo-se em conta um saber do direito que reflita tais questões.

\section{BIBLIOGRAFIA}

ALMEIDA, Luís Nunes de - "Tolerância, Constituição e Direito Penal", in Revista Portuguesa de Ciência Criminal, ano 13, n. 2, Abril-Junho 2003, p. 159-175.

BAUDRILLARD, Jean. "Die Transparenz des Bosen - Ein essay uber extreme phânomene”. Berlim, 1992.

BERLIN, I. "Quatro ensaios sobre a liberdade”. Tradução de Wumberto Hudson Ferreira. Brasília, DF: Ed. da UNB, 1981.

BURDEAU, G. Les libertés publiques. 4. ed. Paris: Press Universitaires de France, 1972. 
COUlAngES, F. “A Cidade Antiga”. Tradução de Fernando de Aguiar. Lisboa: Clássica, 1971.

FISS. Owen M. A Ironia da Liberdade de Expressão: Estado, Regulação e Diversidade na Esfera Pública. Rio de Janeiro: Ed. Renovar, 2005.

FORST, Rainer. "The Limits of Toleration”, in Constellations, vol. 11, 2004, 312-325 (versão inglesa de Rainer FORST, "Grenzen der Toleranz", in Winfried BRUGGER/Görg HAVERKATE, Grenzen als Thema der Rechts- und Sozialphilosophie, Archiv für Rechtsund Sozialphilosophie, 1998, Beiheft 84;

FORST, Rainer. “Os limites da tolerância”. Novos estud., CEBRAP, São Paulo, n. 84, 2009, p. $15-29$.

GAUDÊNCIO, Ana Margarida Simões. "O intervalo da tolerância nas fronteiras da juridicidade: fundamentos e condições de possibilidade da projecção jurídica de uma (re)construção normativamente substancial da exigência de tolerância". Coimbra, Portugal: Instituto Jurídico da Faculdade de Direito da Universidade de Coimbra. 2019.

HAN, Byung-Chul. "Sociedade do Cansaço". Petrópolis, RJ: Vozes, 2017.

KAUFMANN, Arthur - “Rechtsphilosophie”, C. H. Beck, München, 1997, também citado na tradução portuguesa "Filosofia do Direito", tradução de ULISSES CORTÊS, Antônio. Fundação Calouste Gulbenkian, Lisboa, 2004.

LEE, Simon. "The Cost of Free Speech". Londres: Faber and Faber, 1990.

LOCKE, Jonh. "Cartas acerca da tolerância: segundo tratado sobre o Governo". São Paulo: Abril Cultural, 1973.

MILTON, John. “Aeropagítica”. Cambridge, MA: Cambridge Press, 1918.

POPPER, Karl. "The Open Society and Its Enemies", vol. 1, "The Spell of Plato" e vol. II The High Tide of prophecy: Hegel, Marx, and the Aftermath" (1945), Routledge, United Kingdom, Princeton University Press, 1971.

POPPER, Karl - "Toleration and Intellectual Responsibility", in Susan MENDUS, David EDWARDS, On Toleration, Clarendon Press, Oxford, 1987.

MACHADO, Jónatas. E. M. “Liberdade de expressão: dimensões constitucionais da esfera pública no sistema social”. Coimbra: Coimbra Editora, 2002.

ROSANVALLON, Pierre. “A crise do Estado-Providência”. Goiania: Editora da UFG, 1997. 
SARMENTO, Daniel. "A liberdade de expressão e o problema do "Hate Speech". In: SARMENTO, Daniel. "Livres e iguais: estudos de Direito Constitucional". Rio de Janeiro: Lumen Juris, 2006.

SILVEIRA, Renata Machado da. "Liberdade de expressão e discurso do ódio". Dissertação de Mestrado. PUC/MG, 2007.

VOLTAIRE (François Marie Arouet). "Tratado sobre a tolerância: a propósito da morte de Jean Calas”. 2. ed. São Paulo: Martins Fontes, 2000.

WALDRON, Jeremy. "Dignity and Defamation: the Visibility of Hate". Harvard Law Review, v.123, n.1596, p. 1597-1657, 2010.

WALDRON, Jeremy. "The harm in the hate speech". Cambridge, Massachussets: Harvard University Press, 2012. 